\title{
Aprendre amb una pissarra digital
}

\author{
Toni Serrano \\ IES Sant Quirze \\ aserran5@xtec.cat
}

"Entre els recursos que les noves tecnologies (TIC) posen a l'abast dels docents, la 'pissarra digital' constitueix, sens dubte, el que proporciona un major potencial didàctic, alhora que indueix una progressiva introducció de pràctiques innovadores i centrades en l'activitat de l'estudiant" (Pere Marquès).

Paraules clau: PDI, pissarra digital interactiva, Toolkit, Flash

\section{De la pissarra interactiva al joc "interactiu"}

La pissarra digital interactiva consisteix en una instal-lació a l'aula d'un projector, un ordinador o qualsevol tipus de reproductor de vídeo i una pantalla (si és possible, sensible al tacte) de la qual depèn el seu grau d'interactivitat.

Aquest recurs té tot un seguit d'avantatges:

- Millora la motivació i l'atenció de l'alumnat

- Permet fer les classes més atractives i vistoses

- Potencia la participació i la discussió de l'alumnat

- Augmenta la interacció professor- alumnes i entre matèria i tecnologia

- Optimitza el temps disponible per a l'ensenyament

- És aplicable a totes les etapes educatives

- Facilita la comprensió, potenciant les explicacions de manera visual (a través de vídeos i imatges) i auditiva

- S'acomoda als diferents tipus d'ensenyaments

- Serveix tant per al treball individual com de grup

- Afavoreix el pensament crític i el treball constructivista, ja que els alumnes tenen un paper més actiu

- Fomenta l'espontaneïtat i la flexibilitat

- És excel-lent per fer videoconferències i afavoreix l'aprenentatge cooperatiu

- Permet atendre la diversitat d'alumnat
Hi ha molts models d'aplicació de la pissarra digital: suport a les explicacions del professorat, suport a les presentacions dels alumnes, correcció col-lectiva d'exercicis a classe, videoconferències, per crear una bitàcola o diari de classe, realització de jocs col-lectius a l'aula... Tots poden conviure sense problemes en el desenvolupament normal de les classes i l'elecció d'un o més d'aquests models dependrà del tema o la nostra forma de treballar.

Com a docents ens preguntem: "S'aprèn jugant? Com conduir aquest procés d'aprenentatge a través del joc?"

Per descomptat que tots estaríem d'acord que l'adquisició dels coneixements i el desenvolupament de les habilitats és molt més sòlid si s'introdueixen activitats lúdiques que "reforcin" els continguts teòrics treballats en les nostres classes. Però segur que tots hem fet dues objeccions a aquest principi:

- És cert, però és més adequat per a l'etapa infantil...

- El programa és molt llarg i el curs molt curt...

Us proposo un sistema: "crear-aprendre-jugar". Es tracta de proposar als alumnes la creació de jocs que després utilitzarem per a jugar amb la pissarra digital. Els alumnes no només aprendran jugant, hauran après a casa creant l'activitat. I, sens dubte, el factor motivació està assegurat! 


\section{Les eines Toolkit del programa Smart}

Independentment del model de pissarra interactiva que teniu al vostre centre, podeu descarregar de forma gratuïta el programari de la marca "Smart" si seguiu aquest enllaç:

http://www2.smarttech.com/st/en-US/Support/SBS/

i instal-lar-lo a l'ordinador de l'aula PDI i, si en disposeu, també a un grup d'ordinadors amb els que podeu treballar amb els alumnes.

El programari "Smart" té unes increïbles possibilitats, però per a aquest treball ens en centrarem en una part: les "eines toolkit".

Obriu el programa "Notebook 10" i trieu la segona pestanya, Galeria, de la barra d'eines que trobareu a l'esquerra. Del menú, escolliu "Lesson Activity Toolkit" (fig. 1).

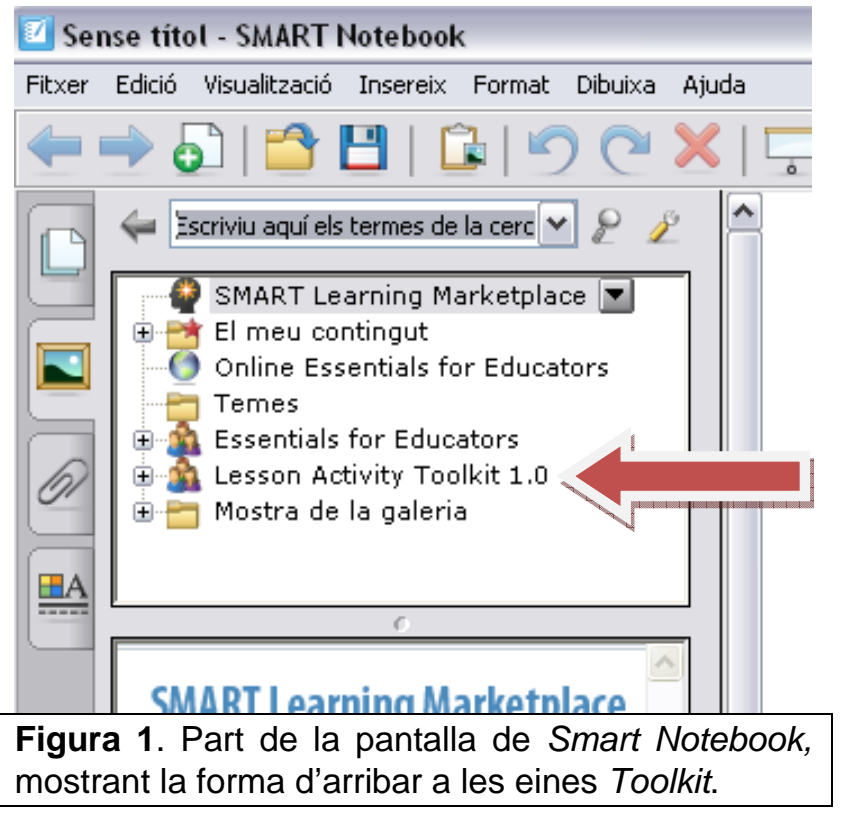

Aquesta eina permet "crear" jocs interactius en Flash sense necessitat de ser un expert en informàtica, ja que conté una completa col·lecció personalitzable d'eines i plantilles (activitats, jocs, gràfics...).

El contingut de la lliçó s'organitza en carpetes o podeu fer una cerca dels objectes amb el quadre de recerca de temes (fig. 2).

A part inferior podeu seleccionar unes plantilles diferents que es poden utilitzar per mantenir als vostres alumnes motivats i aconseguir que l'aprenentatge sigui divertit. Hi ha molts tipus d'activitats, totes editables, jocs...

\section{Escriviu aquí els termes de la cerc $\boldsymbol{V}$}

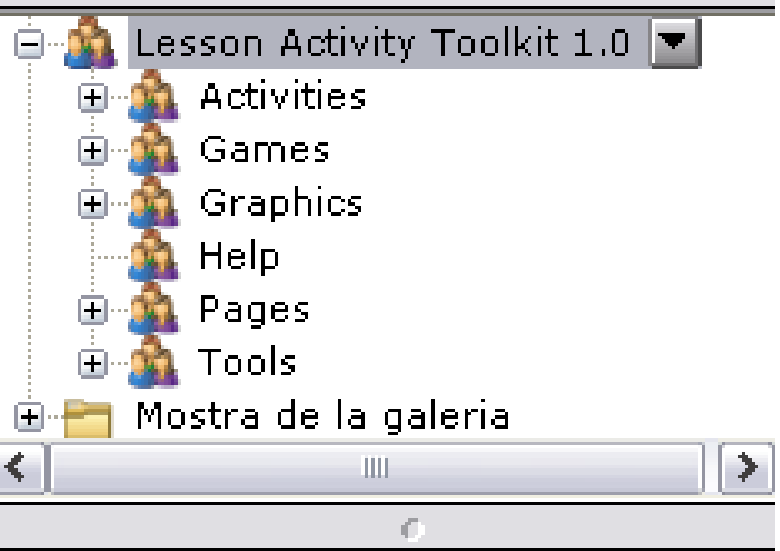

Lesson Activity Toolkit 1.0

563 elements

\begin{tabular}{|l|l|}
\hline & Imatges i fons (332) \\
\hline & Interactiu i multimèdia (92) \\
\hline & Fitxers i pàgines del Notebook (13 ... \\
\hline
\end{tabular}

Figura 2. Vista parcial de la pàgina Lesson Activity Toolkit.

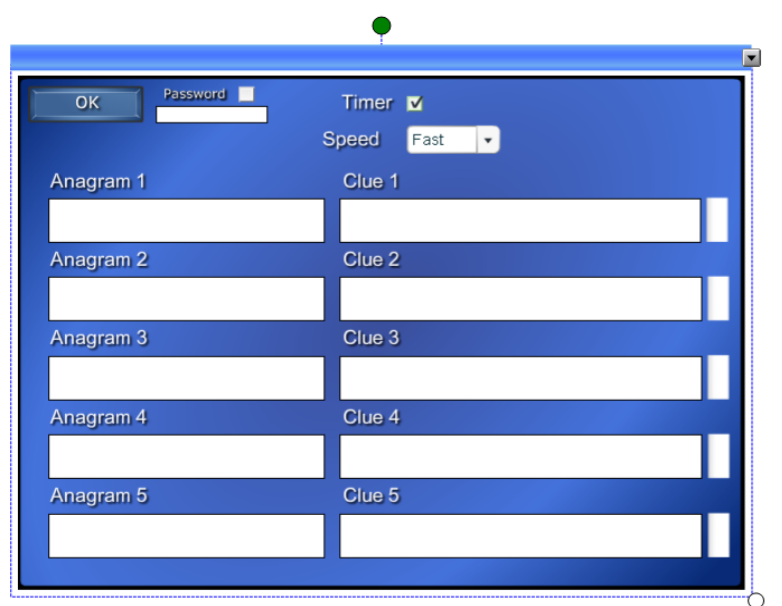

Figura 3. Una de les plantilles per a la confecció d'un joc.

A la fig. 3 veieu un exemple que podeu realitzar a la pissarra digital per explicar als vostres alumnes la tasca que hauran de fer:

- Trieu un model de la segona barra de color blau "interactiu i multimèdia" (fig. 2). Jo he escollit 
"Anagram". Arrossegueu a l'espai blanc de treball.

- Ara, cliqueu "editar"

- A "Anagram1, 2, 3..." (fig. 3) poseu les paraules clau del tema que voleu treballar. A "Clue 1, 2 , 3...", les pistes.

- Podeu determinar un temps i la velocitat. Per assegurar-vos que no es pot modificar el joc teniu fins i tot, l'opció "password".

- Cliqueu OK i ja teniu preparat un senzill joc (fig. 4) que dóna, fins i tot, puntuació en funció dels objectius proposats!

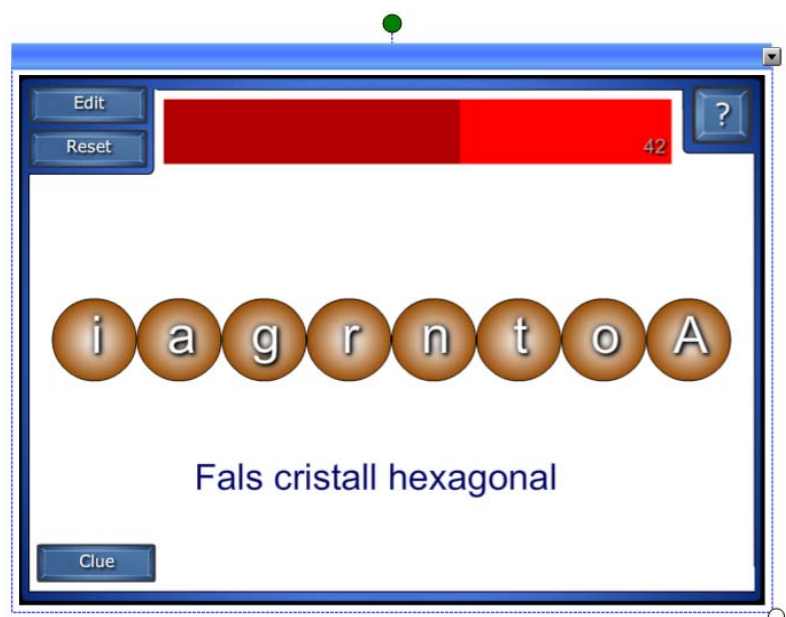

Figura 4. Aspecte que té el joc per a l'alumnat.

Ara, només cal que proposeu als vostres alumnes que "dissenyin" jocs amb aquesta eina a partir del tema treballat. No cal que justifiquem aquí la importància del joc com a recurs, ja que aporta noves formes per explorar la realitat $i$ estratègies dife- rents per a treballar-hi. Permet la creació d'un espai reservat a l'espontaneïtat. Ajuda als nostres alumnes a descobrir noves cares de la imaginació, pensar en nombroses alternatives per a un problema, desenvolupar diferents mètodes i estils de pensament i afavoreix un canvi d'actitud que es pot enriquir i diversificar a l'intercanvi grupal.

Cada grup treballa, recerca i crea sobre el tema en funció de les seves capacitats i possibilitats maduratives i creatives. Es garanteix així l'adequació d'aquesta activitat a la diversitat de la classe.

Però el més important, jo crec, és que aquesta eina propicia el fet de fer-ho amb el "llenguatge" dels nostres alumnes, on el joc electrònic és una realitat tan present a la seva forma de construir el seu pensament com seria per a nosaltres un llibre.

\section{Webgrafia}

Marquès, Pere. Acta de la Jornada DIM de Navidad 2007. Desembre, 2007.

Consulta 10/5/2009

http://www.pangea.org/dim/reunionnadal2007.ht $\mathrm{m}$

Safont, Elvira. La pissarra digital. 2005. Consulta 10/5/2009 http://www.xtec.net/ esafont/

Segué, Txel.li. La pissarra digital. Març, 2008. Consulta 10/5/2009

http://www.xtec.cat/ msegue/pdi.htm

Web home de Smart Technologies. Maig, 2009. Consulta 10/5/2009 http://smarttech.com/

Manuela, León i altres. Los juegos: métodos creativos de enseñanza. Maig 2008. Consulta 10/5/2009

http://www.neuronilla.com/Los\%20juegos, \%20m etodos\%20creativos\%20de\%20enseñanza.pdf 